\title{
Solitary Cyst of Kidney
}

National Cancer Institute

\section{Source}

National Cancer Institute. Solitary Cyst of Kidney. NCI Thesaurus. Code C122992.

A sing le cyst located in the kidney. 